\title{
Dedifferentiation, Transdifferentiation, and Reprogramming: Future Directions in Regenerative Medicine
}

\author{
Cristina Eguizabal, $\mathrm{PhD}^{1}$ Nuria Montserrat, $\mathrm{PhD}^{1}$ Anna Veiga, $\mathrm{PhD}^{1,2}$ \\ Juan Carlos Izpisua Belmonte, $\mathrm{PhD}^{1,3}$
}

${ }^{1}$ Center for Regenerative Medicine in Barcelona

2 Reproductive Medicine Service, Institut Universitari Dexeus,

Barcelona, Spain

${ }^{3}$ Gene Expression Laboratory, The Salk Institute for Biological Studies, La Jolla, California

\begin{abstract}
Address for correspondence and reprint requests Juan Carlos Izpisua Belmonte, PhD, Gene Expression Laboratory, The Salk Institute for Biological Studies, 10010 North Torrey Pines Road, La Jolla, CA 93027 (e-mail: belmonte@salk.edu).
\end{abstract}
Abstract
Keywords
- regenerative medicine
- stem cells
- dedifferentiation
- transdifferentiation
- reprogramming

The main goal of regenerative medicine is to replace damaged tissue. To do this it is necessary to understand in detail the whole regeneration process including differentiated cells that can be converted into progenitor cells (dedifferentiation), cells that can switch into another cell type (transdifferentiation), and somatic cells that can be induced to become pluripotent cells (reprogramming). By studying the regenerative processes in both nonmammal and mammal models, natural or artificial processes could underscore the molecular and cellular mechanisms behind these phenomena and be used to create future regenerative strategies for humans.
To understand any regenerative system, it is crucial to find the cellular origins of renewed tissues. Using techniques like genetic lineage tracing and single-cell transplantation helps to identify the route of regenerative sources. These tools were developed first in nonmammal models (flies, amphibians, and fish) and then in mammal models like mice. The source of cells during regeneration in most cases is either stem cells or progenitor cells, or the dedifferentiated or transdifferentiated cells within the tissue of origin. Another process related to regenerative therapies is reprogramming: somatic cells that can be converted into stem cells, known as induced pluripotent stem cells (iPSs). These artificial stem cells are suitable for several purposes: basic research, drug screening, disease modeling, or autologous cell therapy.

The promising future of regenerative medicine is to replace or regenerate tissues or organs to restore or reestablish normal cell function. To do so, it is necessary to understand the three regenerative processes: dedifferentiation, transdifferentiation, and reprogramming. By using the model developed by Waddington ${ }^{1,2}$ (- Fig. 1), it is possible to understand the epigenetic status and the developmental potential of each cell during these processes. This modified schematic representation explains graphically how cells lose potency and differentiate and how they can revert to pluripotency (reprogramming) or switch lineages (dedifferentiation and transdifferentiation).

We synthesize the studies of different model systems to highlight recent insights that are integrating the field. Whereas previous reviews largely focused on specific animal models, molecular pathways, or only on one regenerative route, our aim is to combine the three regenerative routes in several species and discuss future directions in regenerative medicine.

\section{Dedifferentiation}

Dedifferentiation is the reverse developmental process in which differentiated cells with specialized functions become undifferentiated progenitor cells. Dedifferentiation and subsequent proliferation provide the basis for tissue regeneration and the formation of new stem cell lineages.

\section{In Vivo Dedifferentiation}

Historically, the first evidence of dedifferentiation during the regeneration process was found in plants. ${ }^{3}$ Basically, it can be divided into different types: the regeneration of a tissue
Issue Theme Stem Cells Helping Reproductive Medicine; Guest Editor, Carlos Simón, MD, PhD
Copyright (c) 2013 by Thieme Medical Publishers, Inc., 333 Seventh Avenue, New York, NY 10001, USA. Tel: +1(212) 584-4662.
Dol http://dx.doi.org/ $10.1055 / \mathrm{s}-0032-1331802$. ISSN 1526-8004. 


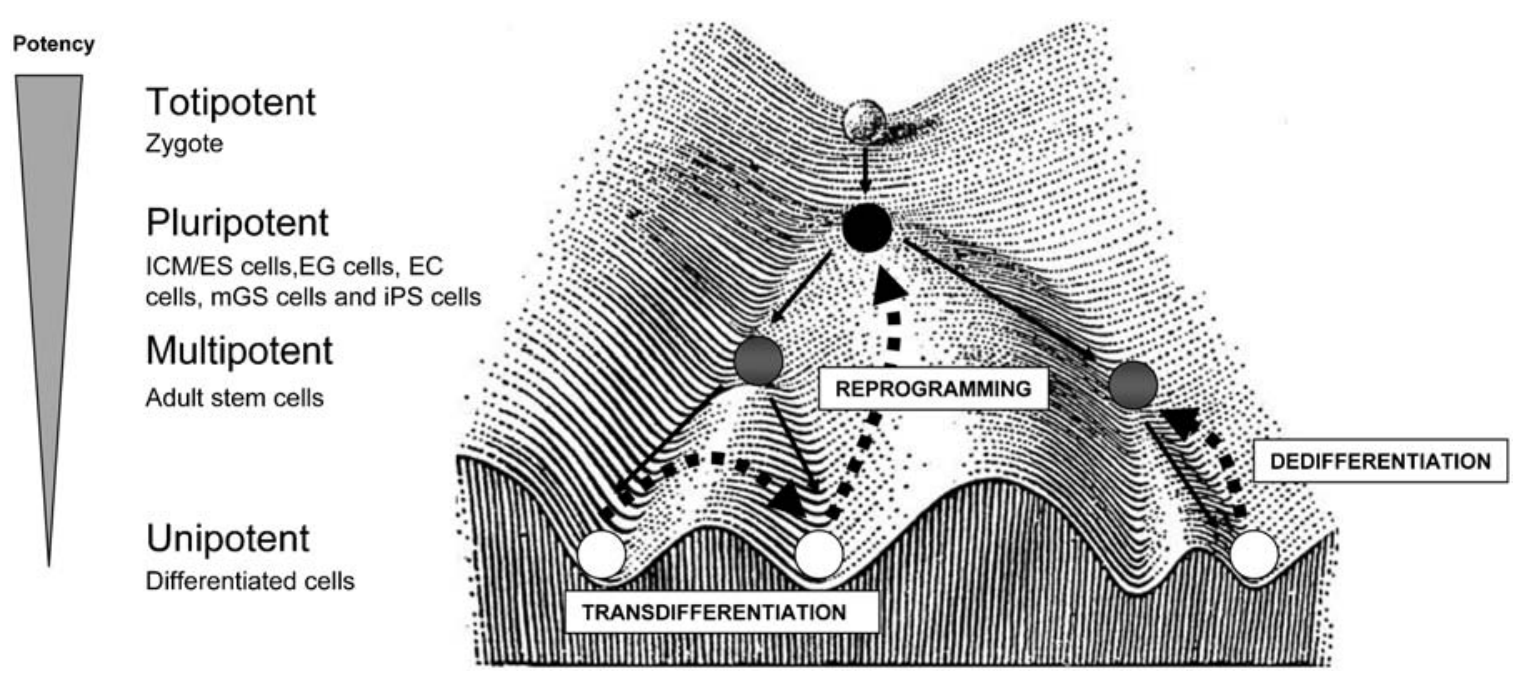

Figure 1 Dedifferentiation, transdifferentiation, and reprogramming processes in Waddington's epigenetic landscape shows cell populations with different epigenetic and developmental potentials. A modification of the original and modified Waddington's landscape. ${ }^{1,2}$ EG cells, embryonic germ cells; EC cells, embryonic carcinoma cells; ICM/ES cells, inner cell mass/embryonic stem cells; iPS cells, induced pluripotent stem cells; mGS cells, multipotent germline stem cells.

structure lost after an injury, the de novo generation of a new tissue structure not present before the injury, and the regeneration of the whole plant from a single somatic cell. ${ }^{4}$ Recent studies on the generation of callus have shown that it regenerates due to a preexisting pluripotent stem cell population instead of a dedifferentiation process. ${ }^{5}$ More studies are still needed to evaluate this discrepancy.

In nonmammalian vertebrates, there are several examples of dedifferentiation; one of them is bone regeneration via dedifferentiation of the osteoblast in zebrafish fin. ${ }^{6} \mathrm{Knopf}$ and colleagues monitored osteoblast differentiation in the regenerating fin using a transgenic system expressing fluorescent proteins under the control of promoters of early, intermediate, and late osteoblast-specific genes (RUNX2, SP7, and BGLAP [osteocalcin]). ${ }^{7-9}$ Their elegant study showed that in a response to the amputation, mature osteoblasts dedifferentiate, become proliferative, and migrate distally to form outer regions of the regeneration of blastema of fin rays.

Another example of dedifferentiation occurs during heart regeneration in zebrafish. Jopling and colleagues ${ }^{10}$ described that zebrafish heart can fully regenerate up to $20 \%$ after amputation in the ventricle. ${ }^{11-13}$ To explain these data, the authors generated induced green fluorescence protein (GFP) transgenic zebrafish under cardiomyocyte-specific promoters (mlc2a and gata4). During this regeneration process, fully differentiated cardiomyocytes can dedifferentiate and proliferate, regenerating the missing part of the ventricle. ${ }^{10,14}$ GFP-labeled cells indicated that the newly generated cardiomyocytes originated from existing GFP cardiomyocytes and not from a source of progenitors.

Another good example of dedifferentiation is limb regeneration in urodeles (salamander). At first the blastema (group of cells that initiates the regenerative process) was regarded as a homogeneous cell population, but it was later demonstrated to be a heterogeneous cell population containing progenitor cells with restricted potential. A specific cell lineage analysis revealed that the regenerating cells maintaining the memory of the earlier cellular identity give rise to tissues only within their original lineage. ${ }^{15} \mathrm{~A}$ recent controversial study in Xenopus limb regeneration confirmed the important role of SALL4 in the dedifferentiation and maintenance of the blastema cells in an undifferentiated state. More studies on limb regeneration are needed to elucidate the real mechanisms involved in limb regeneration in amphibians.

In the case of tail regeneration in the axolotl, tracking fluorescent-labeled single muscle fibers and observing the mononuclear state of muscle fiber cells as a "less differentiated" state, muscle cells confirmed the dedifferentiation of mature fibers. In the same manner, authors observed an increase of the transcription factor MSX-1, known to be expressed in early development during epithelial-mesenchymal transition. Taken together, all of this provides evidence that the terminally differentiated myotubes dedifferentiated toward multipotent cells. ${ }^{16-19}$

The dedifferentiation process has been shown to be related to the entry of the regenerating cells into the cell cycle. It has been observed that during regenerative dedifferentiation, the tumor suppressor retinoblastoma protein (RB) plays a key role in the reentry of the cells into cell cycle. Along these lines, it has been shown that Drosophila melanogaster mutants for RB and Hippo (a member of the STE20 family of protein kinases) maintain a normal neuronal differentiation program. However, the cells do not retain their differentiated status. They dedifferentiate to an earlier eye-precursor stage showing unrestricted proliferation. So far, it seems that dedifferentiation and the cell cycle processes are distinct from one another and that RB also plays an important role in maintaining the differentiated status of the cell. ${ }^{20,21}$

In mammals, the capacity of regeneration following the dedifferentiation strategy is limited. However, it has been observed that in the mouse model, Schwann cells possess the natural ability to regenerate. During development, Schwann 


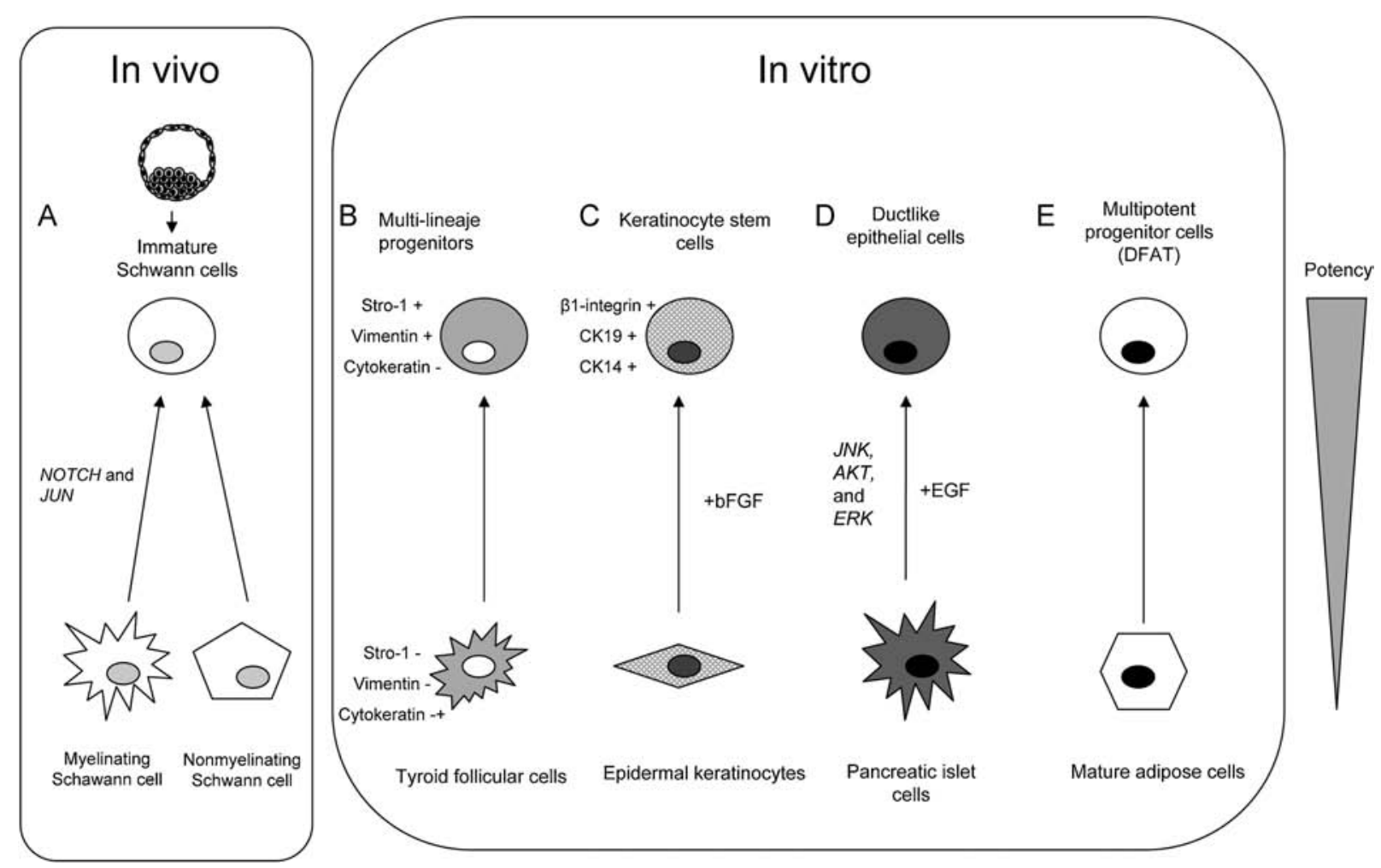

Figure 2 In vivo and in vitro dedifferentiation in mammals. (A) Schwann precursors dedifferentiate toward immature Schwann cells and then finally differentiate into mature myelinating or nonmyelinating Schwann cells. (B) Human tyroid follicular cells can be dedifferentiated into multilineage progenitor cells by culturing them in serum-free conditions. (C) Human epidermal keratinocytes dedifferentiate into precursor cells. (D) Adult human islet cells can be converted back into ductlike epithelial structures. (E) Mature adipocytes can go back into lipid-free fibroblast-like cells, named dedifferentiated fat (DFAT).

precursors dedifferentiate toward immature Schwann cells and then finally differentiate into mature myelinating or nonmyelinating Schwann cells. The precursor cell proliferates, whereas the mature cell does not. After nerve injury Schwann cells dedifferentiated and proliferated at the same time. After local damage, mature Schwann cells lose contact with the axon caused by local damage, they dedifferentiate, and, before proliferating, they begin again to express genes that are linked to immature Schwann cells (NOTCH and JUN) causing the demyelination of the mature cells and promoting the dedifferentiation ${ }^{22-24}$ ( - Fig. 2A).

\section{In Vitro Dedifferentiation}

Myotubes can dedifferentiate and proliferate in newts in vivo, whereas this has not been demonstrated in mice. Two genes have been shown to be crucial for this process (MYOD and MYOG [myogenin]). After treating mouse myotubes with extracts from regenerating limbs of newts, these two genes were downregulated, ${ }^{25}$ which allows myotubes to dedifferentiate and proliferate.

Several examples of dedifferentiation in humans have recently been published. Human tyroid follicular cells can be dedifferentiated into multilineage progenitor cells by culturing them in serum-free conditions. It has been reported that after 4 weeks in culture, the human tyroid follicular cells gain the expression of typical markers of progenitor cells
(STRO-1, vimentin) and lose other differentiation markers (cytokeratin-18) ${ }^{26}$ (-Fig. 2B).

Human epidermal keratinocytes dedifferentiate into precursor cells in vitro in the presence of basic fibroblast growth factor (bFGF) with no external gene intervention. After seven passages the terminally differentiated keratinocytes initiate dedifferentiation by the re-expression of biological markers of native keratinocyte stem cells including $\beta 1$-integrin, CK19, and $\mathrm{CK} 14^{27}$ (-Fig. 2C).

Recent data showed that in the presence of epidermal growth factor in an in vitro culture system, adult human islet cells could be converted back into duck-like epithelial structures. During this islet cell dedifferentiation plasticity, some genes have been identified as "plasticity inducers" (JNK, AKT, and $E R K)^{28}$ (-Fig. 2D).

Fat cells provide another example of in vitro dedifferentiation in humans. Mature adipocytes have been considered as a terminally differentiated lineage with no capacity for proliferation. However, a simple ceiling culture system allows mature adipocytes to go back into lipid-free fibroblast-like cells, named dedifferentiated fat (DFAT). These DFAT have the features of multipotent stem cells with adipogenic, osteogenic, chondrogenic, and myogenic potential ${ }^{29}$ (-Fig. 2E).

Studies on the role of RB and RB-like 2 demonstrated that dedifferentiation of mature cardiomyocytes can facilitate their proliferation in hypertrophic hearts. ${ }^{30}$ Further studies 
using a combination of FGF1 stimulation and p38 MAPK inhibition can induce mammalian cardiomyocytes to dedifferentiate and to disassemble their contractile machinery before proliferating. ${ }^{31-33}$ However, other experimental data suggest that such dedifferentiation may not be necessary for cardiomyocyte proliferation. It has been demonstrated that proliferation can be promoted by neuregulin, an extracellular ligand for ERB receptor, important during cardiomyocyte development, that also reenters cardiomyocytes into the cell cycle. ${ }^{34-36}$

\section{Transdifferentiation}

Transdifferentiation means the irreversible conversion of cells from one differentiated cell type to another. Normally dedifferentiation and cell division are essential intermediate processes in the switch in phenotype, but they may not be obligatory in all cases. Some authors have considered that it does not occur at all in nature. There is good evidence, however, that it does occur in some cases, particularly in situations where missing parts regenerate in animals. ${ }^{37}$

\section{In Vivo Transdifferentiation}

One well-known example of in vivo transdifferentiation is the Wolffian regeneration of the lens of various species of urodele amphibia (newts and salamanders) and anuran (frogs). In these species, after removal of the lens of the eye, new pigmented epithelial cells (PECs) of the lens regenerate and further differentiate to form a new lens. ${ }^{38}$ This regeneration implicates the inactivation of RB allowing the cells to reenter the cell cycle. ${ }^{39}$ Recently, Day and Beck showed that WNT and bone morphogenetic protein signaling pathways are needed for the transdifferentiation from cornea to lens, with the PITX and WNT genes crucial for this process. ${ }^{40}$

Another well-established example of transdifferentiation is the regeneration of striated muscle in the jellyfish ${ }^{41}$ involving the expression of the homeobox gene $M S X^{42}$

Although transdifferentiation is rare in mammals, the musculature of the mouse esophagus has been found to convert from smooth muscle in the fetus to skeletal muscle during early postnatal development. During this process, smooth muscle cells transform back into myoblasts. They then line up and fuse to form myotubes that become cylindrical skeletal muscle fibers ${ }^{43}$ (- Fig. 3A).

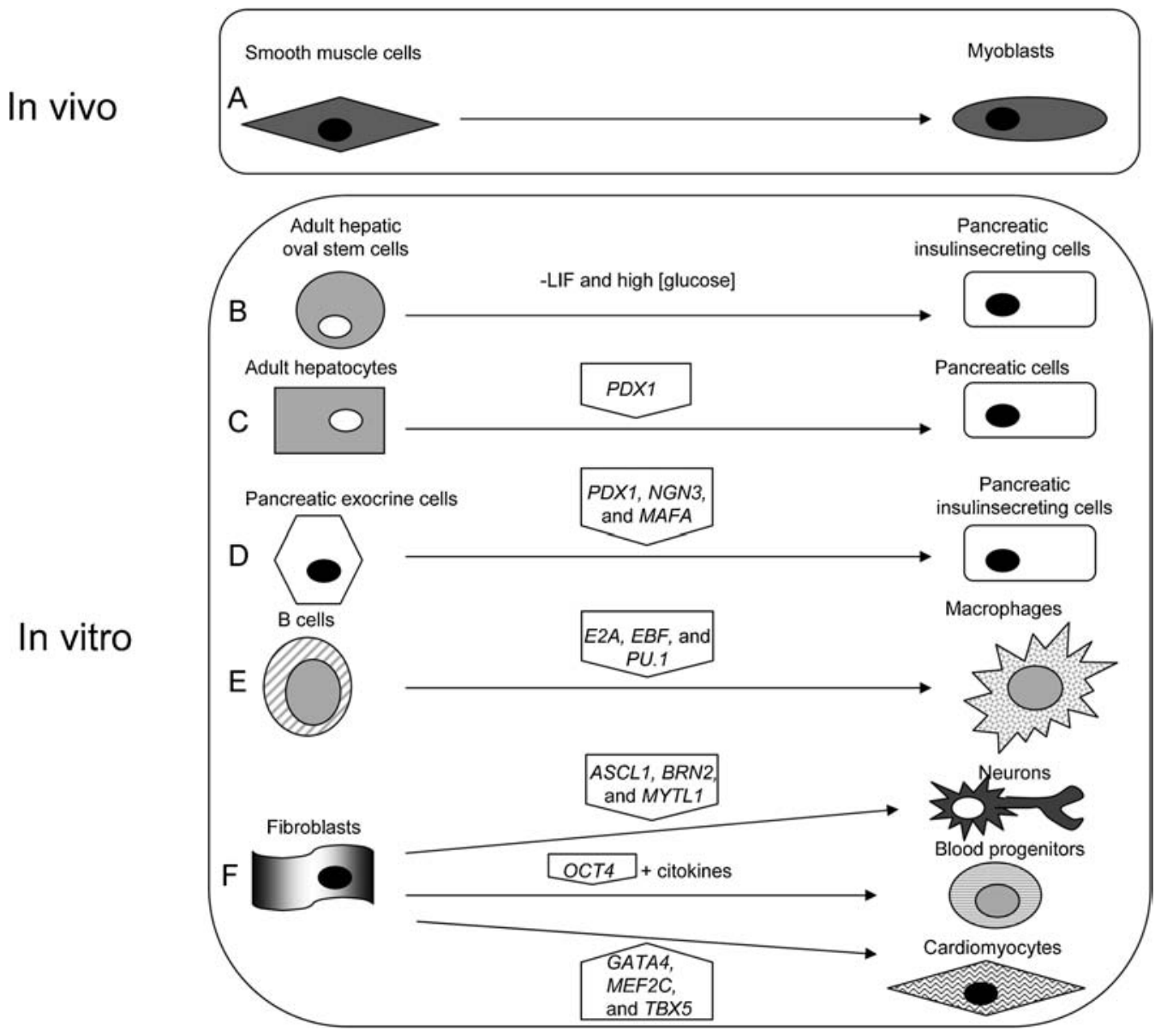

Figure 3 In vivo and in vitro transdifferentiation in mammals. (A) The musculature of the mouse esophagus was found to convert from smooth muscle in the fetus to skeletal muscle during early postnatal development. (B) Hepatic oval stem cells transdifferentiate into functional endocrine cells. (C) Adult hepatocytes trandifferentiate into pancreatic cells. (D) Pancreatic exocrine cells transdifferentiate into insulin-producing $\beta$ cells. (E) Transdifferentiation of $\beta$ cells into macrophages. (F) Fibroblasts transdifferentiate into neurons, cardiomyocytes, and blood progenitors. LIF, leukemia inhibitory factor. 
Another example of transdifferentiation is provided by the liver and the pancreas. These two organs arise from nearby regions of the endodermal epithelium. The FGF signaling pathway has been demonstrated to lead the ventral pancreas to express genes of the liver. ${ }^{44,45}$

\section{In Vitro Transdifferentiation}

Recent studies demonstrated that cultures of purified hepatic oval stem cells exhibit the capacity to transdifferentiate into functional endocrine cells, including insulinsecreting cells, after long-term culture with culture conditions similar to those permitting pancreatic stem cells to differentiate to insulin $\beta$ cells. This transdifferentiation is induced by the removal of leukemia inhibitory factor (LIF) and the increase of glucose concentration in the media. Interestingly, during early stages of the transdifferentiation process, hepatic oval cells show higher levels of expression of the PDX1 gene than terminally pancreatic endocrine hormone-producing cells ${ }^{46}$ (- Fig. 3B). Others have demonstrated that overexpression of PDX1 promotes the transdifferentiation from adult hepatocytes into pancreatic cells inhibiting the transcription factor CCAAT enhancer-binding protein- $\beta$ (CEBP- $\beta$ ), leading to a decrease of the expression of mature hepatocyte genes such as $\alpha$-fetoprotein, glucose6-phosphate, and albumin ${ }^{47}$ (-Fig. 3C). Moreover, pancreatic exocrine cells have been transdifferentiated into insulin-producing $\beta$ cells by expressing PDX1, NGN3, and MAFA genes $^{48-50}$ (-Fig. 3D). Another transdifferentiating route that can be used to produce mature insulin-producing $\beta$ cells is by going through an intermediate cell stage before reaching the complete differentiated cell status. The intermediate cells produce glucagon (produced by $\alpha$ cells) and insulin (produced by $\beta$ cells). ${ }^{51}$

Another example is the experimental transdifferentiation of $\beta$ cells into macrophages. It has been described that three transcription factors (E2A, EBF, and PU.1) are involved in the differentiation to $\beta$ cells during development, which in turn causes the expression of PAX5, which upregulates later specific $\beta$-cell genes. However, during differentiation of macrophages CEBP $\beta, C E B P \alpha$ and PU.1 are present. It has been reported that forced expression of CEBP $\beta$ and CEBP $\alpha$ in differentiated $\beta$ cells leads to reprogram them into macrophages without significant changes in DNA methylation. ${ }^{52,53}$ (-Fig. 3E).

Following a similar strategy, it is possible to transdifferentiate mouse fibroblasts into functional neurons using three transcription factors (ASCL1, BRN2, and MYTL1). The exact mechanism involved in this process is still unknown. ${ }^{54}$ Studies were recently published about the plasticity mechanisms during transdifferentiation of mature neurons. Loy and colleagues identified the $p 38$ gene as the trigger for switching from noradrenergic to cholinergic neurotransmission after exposure to the neuropoietic cytokines ciliary neurotrophic factor and $\operatorname{LIF}^{55}$ (- Fig. 3F)

Fibroblasts have also been transdifferentiated into cardiomyocytes using GATA4, MEF2C, and TBX5. GATA4 initiates the process by opening the chromatin, allowing the other transcription factors access ${ }^{56}$ (-Fig. 3F).
It was recently published that treatment with angiotensin receptor blockers (ARBs) in cultured human mesenchymal stem cells (MSCs) improves cardiomyogenic transdifferentiation efficiency both in vivo and in vitro, and transplantation of ARB pretreated cells could be a promising cardiac stem cell source for replacing damaged cardiomyocytes. ${ }^{57}$

Human dermal fibroblasts have also been transdifferentiated into granulocytic, monocytic, megakaryocytic, and erythroid lineages with in vivo engraftment capacity using the ectopic expression of OCT4 in the presence of specific cytokine treatment ${ }^{58}$ (-Fig. 3F).

\section{Reprogramming}

The reversal of the differentiated state of a mature cell to one typical of the undifferentiated embryonic state is known as nuclear reprogramming. ${ }^{59}$ During this reprogramming process, an erasure and remodeling of epigenetic marks occur such as DNA methylation, histone, and chromatin structure modifications. For a better understanding of this epigenetic event, we first focus on in vivo studies during mammalian development. We then describe the different approaches of in vitro reprogramming such as somatic cell nuclear transfer (SCNT), cell fusion, and spontaneous and direct induced reprogramming.

\section{In Vivo Nuclear Epigenetic Reprogramming}

\section{From Zygote to Blastocyst}

From zygote to blastocyst, cells have to make crucial decisions to allow complete development of the individual. These decisions are related to the activation or silencing of genes in a well-orchestrated manner. The activation or silencing of genes is regulated by epigenetic elements. A good combination of epigenetic elements like DNA methylation, histone modifications, and chromatin structure permit the creation of the correct cells that will form a healthy organism.

The epigenetic program in early mouse development initiates with DNA methylation in the paternal pronucleus of the zygote, followed later by a gradual loss of DNA methylation, and ending by changing the structure of heterochromatin in the inner cell mass (ICM) of the blastocyst linked with X-chromosome reactivation in female embryos. During fertilization, the maternal DNA is surrounded by $\mathrm{H} 1 \mathrm{oo}$ variant substituting $\mathrm{H} 1$ linker histones, probably helping in the decondensation of the maternal chromatin. ${ }^{60}$ By contrast, paternal DNA is compacted using protamines, and after fertilization the genome starts to be decondensed by histones. The histone variants H2AL1/L2 present on the heterochromatin in sperm disappear during the protamine/histone replacement just after fertilization. ${ }^{61,62}$ Also some spermspecific histone variants (H2AL1/L2, tH2B, H3.3, H2A.X, and H2A.Z) are highly expressed during this process. Following fertilization and the extrusion of the second polar body, the maternal and paternal genomes start to decondense at the pronucleus (PN) 1 stage. The protamines compacting the paternal genome are missing and lacking H3K9me2, H3K9me3, and H3K27me3 heterochromatin histone marks, 


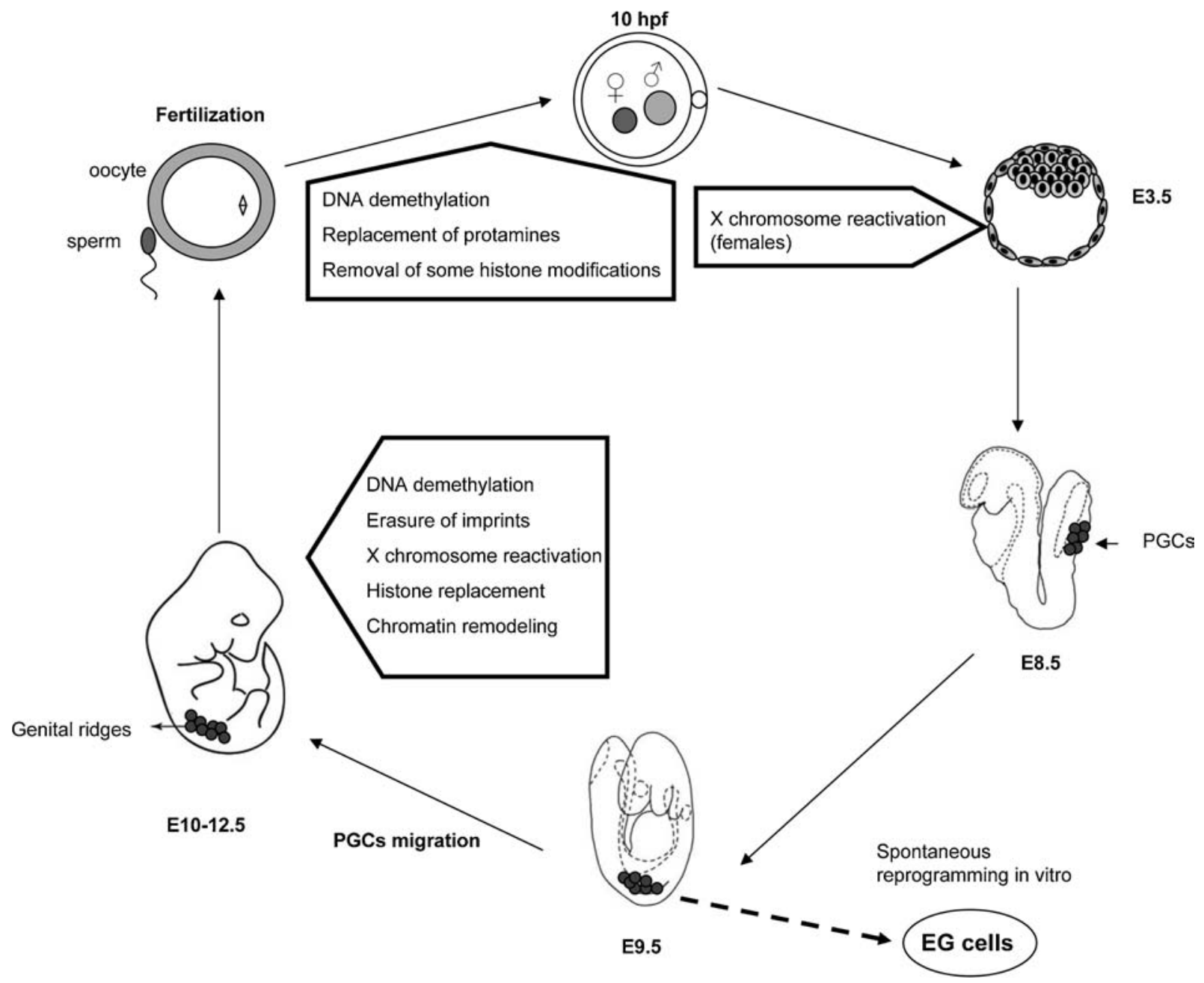

Figure 4 Schematic diagram of the in vivo and in vitro epigenetic changes during epigenetic reprogramming in early mouse development and germline. EG cells, embryonic germ cells; hpf, hours post fertilization; PGCs, primordial germ cells.

whereas these histone modifications are still present in the female pronucleus. ${ }^{63,64}$ Also the $\mathrm{H} 3.3$ variant specifically present in the male pronucleus contributes to this epigenetic asymmetry between parental pronuclei. ${ }^{65,66}$

At the PN2 stage, high levels of DNA methylation are detected in both pronuclei. The loss of the global methylation mark, 5-methyl cytosine (5meC), surprisingly affects only the paternal genome, whereas the levels of maternal DNA methylation remain unaffected. ${ }^{64,67,68}$ This specific paternal demethylation is linked to the lack of repressive histone modification marks: H3K9me2, H3K9me3, and H3K27me3. ${ }^{69,70}$

The culmination of the epigenetic changes in early development appears in the pluripotent cells of the ICM at the blastocyst stage. The formation of the ICM is related to another epigenetic change, the reactivation of the inactive $\mathrm{X}$ chromosome in female embryos ${ }^{71,72}$ (-Fig. 4).

\section{Germline}

The germline is a unique cell type that has the capability to give rise to gametes. The germline is a direct derivation of the pluripotent epiblast of the postimplantation embryo. Follow- ing specification, the primordial germ cells (PGCs) establish a specific transcriptional network similar to the networks of the pluripotent embryonic stem (ES) cells. ${ }^{73}$

In mice, at 8.5 days postcoitum (dpc) PGCs start the migratory process toward the future gonads, the genital ridges. This migration ends around $10.5 \mathrm{dpc}$. In females, the PGCs downregulate the expression of Xist from the inactive $\mathrm{X}$ chromosome $(\mathrm{Xi})$, later followed by a progressive reactivation of Xi-linked silent genes that is completed at $14.5 \mathrm{dpc}^{74,75}$ (-Fig. 3). Once the PGCs are in the genital ridges, the germ cells undergo an epigenetic reprogramming. This reprogramming involves genomewide DNA demethylation, changes in chromatin structure, and loss of several histone modification marks. $^{69,76}$ The DNA methylation affects both single-copy genes (imprinted and nonimprinted) as well as repetitive elements happening only in a window of time lasting a few hours. Interestingly, the onset of DNA demethylation precedes the onset of chromatin changes like the loss of signal for linker histones, H3K9me3, H3K27me3, H2A/H4 R3me2s, and other histone modification marks (-Fig. 4). Both processes occur in the $\mathrm{G} 2$ phase of the cell cycle, demonstrating that the genomewide DNA methylation is an active process. 
Recently, it was proposed that a base excision DNA repair (BER) element in the active DNA demethylation could be involved in PGC epigenetic reprogramming. ${ }^{77}$ However, the exact molecular details of this active DNA demethylation in the germline still remain unknown. This epigenetic reprogramming is needed in this specialized cell type for preventing the formation of aberrant gametes.

\section{In Vitro Nuclear Epigenetic Reprogramming}

\section{Somatic Cell Nuclear Transfer}

The process of SCNT consists of transferring a somatic nucleus into an enucleated oocyte. After being inserted into the oocyte, the somatic cell nucleus is reprogrammed by the cytoplasm of the host oocyte cell. The oocyte, now containing the somatic cell's nucleus, is stimulated with a shock and begins to divide. After many mitotic divisions, this single cell forms a blastocyst with almost identical DNA to the original organism. SCNT can be performed for two different aims: reproductive SCNT with the objective of obtaining cloned animals and therapeutic SCNT with the objective of obtaining embryonic stem cells.

The earliest evidence of nuclear reprogramming in frogs came from the transplantation of the nucleus of gastrula embryo cells into enucleated frog eggs, creating a normal swimming tadpole of Ranna pipiens in 1952 by Briggs and King. ${ }^{78}$ However, they found later that the transfer of an older nucleus of gastrula embryo cells resulted in an abnormal embryo, concluding that cell differentiation involves irrevers- ible nuclear changes. ${ }^{79}$ After this, similar experiments were performed with eggs using Xenopus leavis by Gurdon. ${ }^{80}$ In those experiments, it was found that even when the Xenopus nuclei were transplanted from fully differentiated cells (intestinal epithelial cells), normal fertile frogs of both sexes could be obtained. ${ }^{81}$ Taken together, these first advances pointed out that the process of cell differentiation could be reversible and did not require irreversible nuclear changes.

One of the most important advances in the field of developmental biology was the publication by Wilmut et al in 1998 of the birth of a cloned sheep (Dolly) by transplanting the nucleus of an adult somatic mammary gland cell into an enucleated oocyte ${ }^{82}$ (- Fig. 5A). Later reports ${ }^{83}$ showed that it is possible to successfully clone a mammal (mouse) from an adult postmitotic cell (neuron), suggesting that this might also work in humans.

In the last 10 years, progress has been made producing "clones" for reproductive purposes in several species-cattle, ${ }^{84}$ goats, ${ }^{85,86}$ mice, ${ }^{87}$ and pigs ${ }^{88-90}$-using the nucleus of adult cells (lymphocytes and postmitotic neurons) in the transfer. ${ }^{83,91}$ Another variant of SCNT is to create interspecies clones like the combination between Bos indicus and Bos taurus $^{92}$ or between tiger and cat. ${ }^{93}$ However, in these cases, the interspecies embryo transfers contribute to perinatal death. ${ }^{94}$

Embryonic stem cells from cloned embryos have been derived in several species ${ }^{95-97}$ such as mouse, rabbit, and pig. An important step in this direction has been the
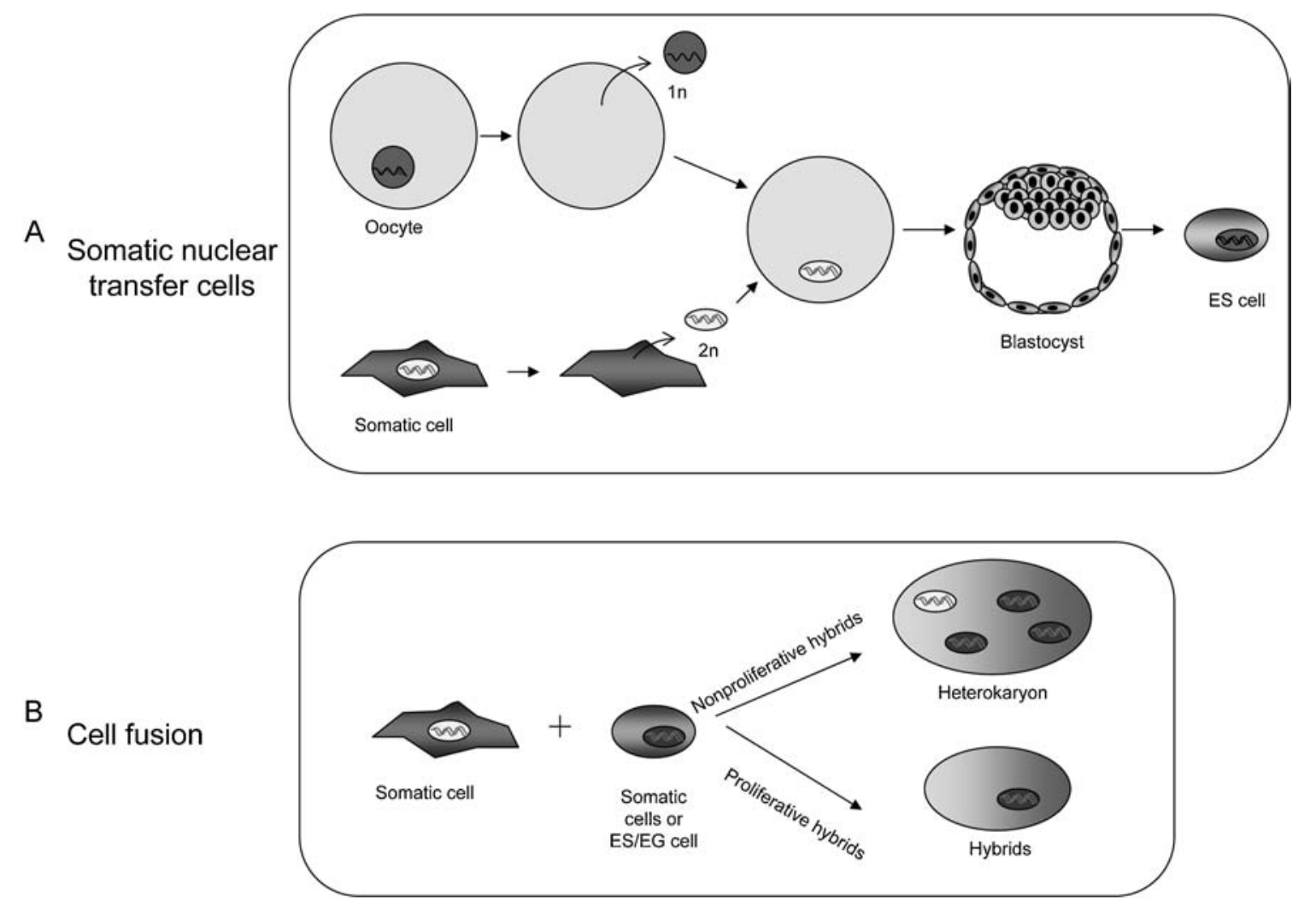

Figure 5 In vitro nuclear epigenetic reprogramming. Approaches to restore pluripotency in somatic cells. (A) Somatic nuclear transfer cells (SNTCs). (B) Cell fusion forming heterokaryons or proliferative hybrids. EG cells, embryonic germ cells; ES cell, embryonic stem cell. 
derivation of monkey embryonic stem cells from blastocysts obtained after the transplantation of an adult nucleus into an enucleated monkey oocyte for regenerative purposes. ${ }^{98}$

Since Dolly the sheep was born, many experiments have been performed in mammals using different donor nuclei cell types (from stem cells to fetal and adult somatic cells) and several donor recipient oocytes at different cell cycle stages, ${ }^{99}$ but unfortunately the efficiency of SCNT has not been improved, limiting the applicability of this method. A fundamental problem is related to the imperfections of the reprogramming following transfer of the nucleus. One reason for this low efficiency is that the cell cycles between donor cells and recipient oocytes should be synchronized. Also the enucleated oocytes must carry the diploid DNA contents after their artificial activation (MII phase). The $G_{0} / G_{1}$ is the most adequate and successful phase for the donor cell. Also M- and $\mathrm{S}$-phase donor cells can be reprogrammed in the MII enucleated oocyte with less efficiency than the previous combination. ${ }^{99-101}$

The second reason for the low efficiency of SCNT can be the donor cell type. In the bovine, Kato and colleagues compared 39 cell types from adults, newborns, and fetuses of both sexes to perform SCNT, but no difference was observed. ${ }^{102}$ Later studies using adult stem cells, such as bone marrow MSCs and hematopoietic stem cells, ${ }^{103,104}$ indicated that the low efficiency observed in SCNT does not only depend on the cell type. It has been shown that it is difficult to complete reprogramming of nuclear transferred oocytes using epigenetic modification of DNA, such as methylation of the imprinted genes in the donor cells. It might be suggested that imprinting status is more important for the success of the cloning than the origin of the donor cells. It is possible that successful cloning requires the use of donor cells with an adequate methylation pattern, which are then reprogrammed in the enucleated oocyte and develop to term. In summary, an adequate methylation status and the origin and cell cycle stage of the donor cell and its differentiation are the critical factors for a successful and efficient SCNT.

\section{Cell Fusion}

Cell fusion is a nuclear reprogramming technique that involves fusing two or more cell types to form a single identity. ${ }^{105}$ Cell fusion can generate heterokaryons or hybrids (-Fig. 5B). One of the first studies in cell fusion created heterokaryons. ${ }^{106}$ These multinucleated fusion cells created by using two different cell types were nonproliferative and short lived. Early studies making heterokaryons by using chicken erythrocytes demonstrated nuclear swelling and DNA and RNA synthesis, although erythrocyte genes were still silenced. ${ }^{107}$ To solve this issue, later studies demonstrated the plasticity of the heterokaryons using muscle and amniotic cells showing that those silent genes could be activated. $^{106,108}$

Several heterokaryons made by fusing mouse muscle cells with different cell types (human fibroblasts, hepatocytes, and keratinocytes) demonstrated that silent muscle genes were activated in each specific cell type of the three germ layers. ${ }^{106,109,110}$ In these studies the DNA methylation status of the heterokaryons was crucial and did not require DNA replication. ${ }^{111,112}$ Taken together, these heterokaryon experiments showed that the silent genes from different differentiated mammalian cells can be converted into other cell types, thereby showing the nuclear plasticity of this differentiated state.

The first evidence of proliferative hybrids was described by Tada and colleagues. ${ }^{113}$ They fused female embryonic germ (EG) cells with thymocytes from adult mice and demonstrated that the tetraploid cells generated were pluripotent. Moreover, the methylation status of imprinted and nonimprinted genes was similar to that found in the germline in vivo. Later, the Tada group showed that after cell fusion the acquisition of pluripotency originated from the ES cell portion. ${ }^{114}$ By contrast, the imprinted genes in the fused tetraploid cells were not demethylated as they are in the germline.

Other groups have described the generation of tetraploid hybrids using human somatic cells and human ES cells. ${ }^{115}$ When comparing generation of heterokaryons versus hybrids, heterokaryons are generated more rapidly and efficiently than hybrids, making them useful for detecting the molecular mechanisms underlying nuclear reprogramming. ${ }^{116,117}$ One possible mechanism that may account for this is the same as that used for DNA repair during in vivo epigenetic reprogramming in the germline. ${ }^{69,118}$

\section{Spontaneous Reprogramming in Germ Cells}

Mammalian PGCs are capable of undergoing spontaneous reprogramming in in vitro conditions giving rise to pluripotent cells called EG cells.

Mouse and human PGCs are embryonic precursors of the germ lineage, which are restricted to form only male and female gametes. PGCs are unique cell types that show expression of some key pluripotency-specific genes and do not form chimeras when injected into blastocysts.

A cell culture system using exogenous signaling molecules (FGF2, LIF, and SCF) is capable of inducing reprogramming of mouse PGCs isolated from 8.0- to 12.5-dpc-old embryos into EG cells ${ }^{119}$ (-Fig. 6A). Interestingly, the presence of FGF2 is crucial for the first 24 hours of the culture. ${ }^{120}$ This reprogramming takes 10 days; pluripotency is assessed by the ability to make chimeras afterward. ${ }^{120}$ Several mutations in DND, PTEN, PGCT1, and AKT genes improve the efficiency in the generation of EG cells. ${ }^{121-123}$ It has been demonstrated that the gene BLIMP1 has an important role in preventing PGCs from dedifferentiating into a pluripotent state as well as in the upregulation of KLF4 and CMYC genes in this conversion. ${ }^{119}$ The same observation has also been published about the generation of human germlines. ${ }^{124,125}$

\section{Direct Induced Reprogramming}

In 1987 Schneuwly and colleagues found that in Drosophila, the overexpression of certain transcription factors in somatic cells could activate the expression of genes arising from another cell type. ${ }^{126}$ In the same year, another group found the same results in mammals. ${ }^{127}$ One of the breakthroughs of the recent years was published by Takahashi and Yamanaka in 2006 when they discovered that pluripotency can be 


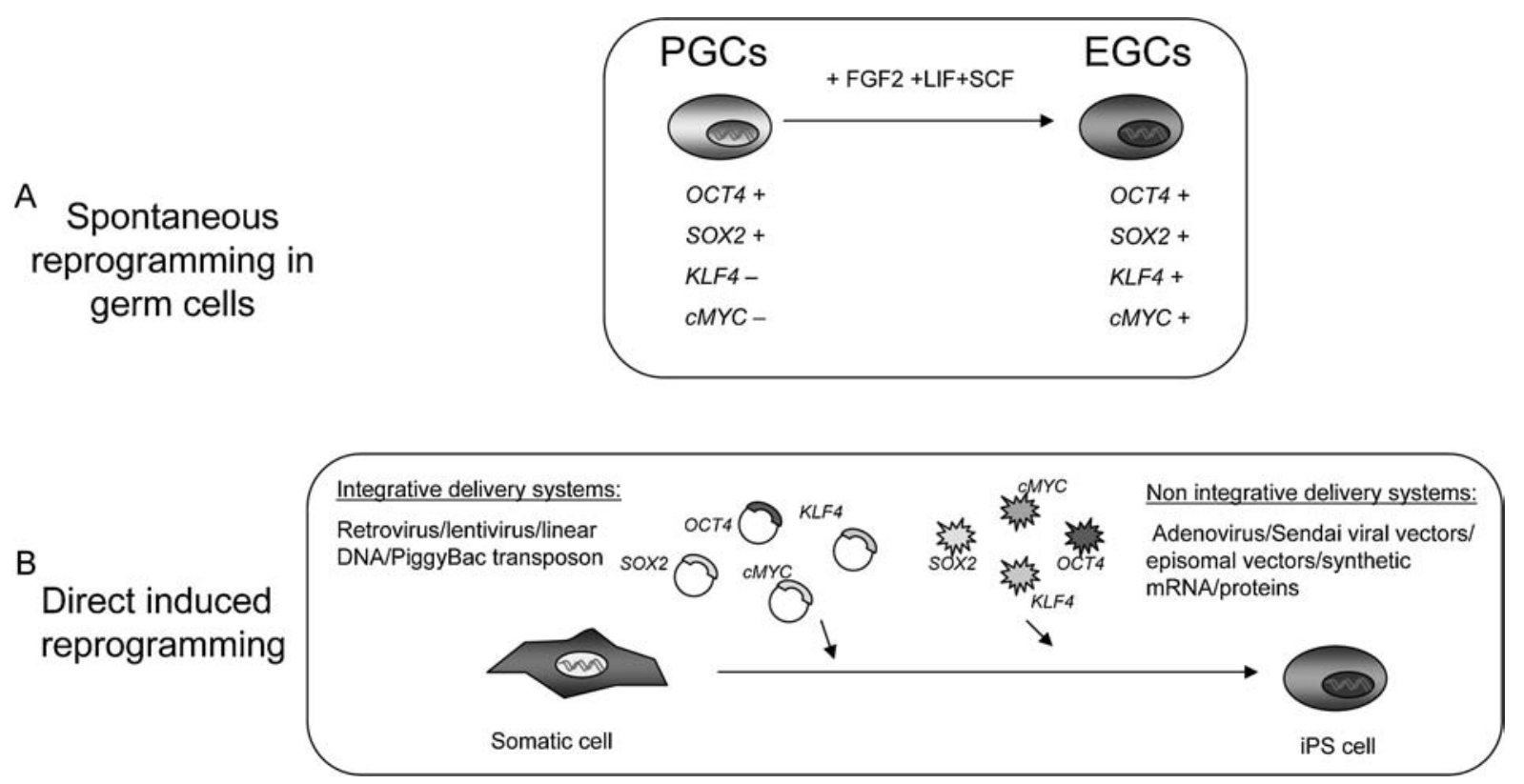

Figure 6 In vitro nuclear epigenetic reprogramming. (A) Spontaneous reprogramming in germ cells, from primordial germ cells to embryonic germ (EG) cells during embryonic development. (B) Direct induced reprogramming using integrative and nonintegrative delivery systems for introducing four transcription factors (OCT4, SOX2, CMYC, KLF4).

regained by several differentiated somatic cell types through the overexpression of just four transcription factors (OCT4, SOX2, cMYC, and KLF4). ${ }^{128-131}$ These cells are called induced pluripotent stem cells (iPSCs). Several factors can be changed during reprogramming such as the number of transcription factors, the strategy for the delivery, and the cell type. Depending on the donor somatic cell type, the reprogramming is achieved with different timings and efficiencies. Mouse embryonic fibroblasts can be reprogrammed in 7 to 12 days, ${ }^{128}$ whereas human foreskin fibroblasts take 20 to 25 days, using retrovirus technology in both cases. ${ }^{132}$ Compared with fibroblasts, human keratinocytes can be reprogrammed 100 times more efficiently and twofold faster. ${ }^{133}$ Also, cord blood CD133 positive cells required only two factors, OCT4 and SOX2, for generating iPSCs. ${ }^{134}$ After choosing the donor somatic cell type, it is then necessary to select a cocktail of reprogramming factors, which usually consist of OCT4, SOX2, KLF4, and MYC, although in a few cases fewer than four factors are needed (cord blood CD133-positive cells and keratinocytes). Chromatin remodeling during reprogramming is also crucial in regaining pluripotency. So far it has been described that the use of some chemical compounds are able to alter DNA methylation or chromatin remodeling for improving reprogramming. Treatment with DNA methyltransferase inhibitors (5'-azacytidine) and histone deacetylase inhibitor (SAHA, TSA, and VPA) improves reprogramming in mouse embryonic fibroblasts. Also, other inhibitors like glycogen synthase kinase 3 (CHIR99021), Parnate (lysinespecific demethylase 1), or G9a inhibitor (BIX-01294) allow reprogramming with only two factors, reviewed in González et al. ${ }^{135}$ Another important step during the reprogramming process is the strategy used for gene delivery. Nowadays there are integrative delivery systems (retrovirus, lentivirus, linear
DNA, and piggyback transposon) and nonintegrative systems (adenovirus, Sendai viral vectors, episomal vectors, synthetic mRNA, and proteins), each of them with pros and cons (-Fig. 6B).

From a clinical point of view, the derivation of iPSCs from patients with genetic syndromes open new opportunities for basic research into these diseases and the development of new therapeutic compounds. iPSCs can be differentiated into a variety of cell types, offering the possibility of an unlimited source of material for disease study. Recently some genetic diseases, like Parkinson disease, spinal muscular atrophy, Hutchinson-Gilford progeria syndrome, Timothy syndrome, and others have been studied using iPSCs as a model to generate differentiated cell types (neurons and cardiomyocytes) for drug testing (ROCK inhibitor, valproic acid, roscovitine, etc. $\left.{ }^{136}\right)$.

\section{Conclusions and Perspectives}

The three processes described in this review show major differences in terms of their in vivo potential. Although dedifferentiation and transdifferentiation can be achieved in vivo, directing pluripotent cells into a new lineage is a complex process that has only been successful in vitro.

So far, none of the three processes described in the current review offers the chance to generate transplantable cells in vivo, although reprogramming and transdifferentiation offer the possibility to generate autologous patient-specific transplantable cells in vitro. Moreover, reprogramming of patientspecific iPSCs offers the possibility to correct the specific mutation(s) leading to the specific disease. Interestingly, the patient's own corrected iPSCs can be differentiated in vitro and further transplanted back into the patient. However, the 
use of specific transcription factors defining target cell identity, a process generally referred to as transdifferentiation, has demonstrated the suitability of such an approach for the direct lineage conversion of human cells into several different lineages. Thus the generation of patient-specific iPSCs and the transdifferentiation of somatic patient cells have changed the way that patient-derived cell products can be applied in regenerative medicine. Both approaches allow for modeling diseases of interest in vitro to elucidate disease mechanisms and circumvent problems related to differences among species that arise when using animal models as well as decreasing patient risks.

\section{Acknowledgments}

The authors thank members of the laboratory for comments on the manuscript. Work in the laboratory of J.C.I.B. was supported by TERCEL-ISCIII-MINECO, CIBER, Foundation Cellex, G. Harold and Leila Y. Mathers Charitable Foundation, and The Leona M. and Harry B. Helmsley Charitable Trust.

\section{References}

1 Waddington $\mathrm{CH}$. The Strategy of the Genes. London, UK: Allen \& Unwin; 1957

2 Hochedlinger K, Plath K. Epigenetic reprogramming and induced pluripotency. Development 2009;136(4):509-523

3 Steeves TA, Sussex IM. Patterns in Plant Development. Cambridge, UK: Cambridge University Press; 1989

4 Sugimoto K, Gordon SP, Meyerowitz EM. Regeneration in plants and animals: dedifferentiation, transdifferentiation, or just differentiation? Trends Cell Biol 2011;21(4):212-218

5 Atta R, Laurens L, Boucheron-Dubuisson E, et al. Pluripotency of Arabidopsis xylem pericycle underlies shoot regeneration from root and hypocotyl explants grown in vitro. Plant J 2009;57 (4):626-644

6 Knopf F, Hammond C, Chekuru A, et al. Bone regenerates via dedifferentiation of osteoblasts in the zebrafish fin. Dev Cell 2011;20(5):713-724

7 Nakashima K, Zhou X, Kunkel G, et al. The novel zinc fingercontaining transcription factor osterix is required for osteoblast differentiation and bone formation. Cell 2002;108(1):17-29

8 Komori T, Yagi H, Nomura S, et al. Targeted disruption of Cbfa1 results in a complete lack of bone formation owing to maturational arrest of osteoblasts. Cell 1997;89(5):755-764

9 Gavaia PJ, Simes DC, Ortiz-Delgado JB, et al. Osteocalcin and matrix Gla protein in zebrafish (Danio rerio) and Senegal sole (Solea senegalensis): comparative gene and protein expression during larval development through adulthood. Gene Expr Patterns 2006;6(6):637-652

10 Jopling C, Sleep E, Raya M, Martí M, Raya A, Izpisúa Belmonte JC. Zebrafish heart regeneration occurs by cardiomyocyte dedifferentiation and proliferation. Nature 2010;464(7288):606-609

11 Poss KD, Wilson LG, Keating MT. Heart regeneration in zebrafish. Science 2002;298(5601):2188-2190

12 Raya A, Koth CM, Büscher D, et al. Activation of Notch signaling pathway precedes heart regeneration in zebrafish. Proc Natl Acad Sci U S A 2003;100(Suppl 1):11889-11895

13 Jopling C, Boue S, Izpisua Belmonte JC. Dedifferentiation, transdifferentiation and reprogramming: three routes to regeneration. Nat Rev Mol Cell Biol 2011;12(2):79-89
14 Kikuchi K, Holdway JE, Werdich AA, et al. Primary contribution to zebrafish heart regeneration by gata $4(+)$ cardiomyocytes. Nature 2010;464(7288):601-605

15 Kragl M, Knapp D, Nacu E, et al. Cells keep a memory of their tissue origin during axolotl limb regeneration. Nature 2009;460 (7251):60-65

16 Echeverri K, Clarke JD, Tanaka EM. In vivo imaging indicates muscle fiber dedifferentiation is a major contributor to the regenerating tail blastema. Dev Biol 2001;236(1):151-164

17 Hay ED. Microscopic observations on muscle dedifferentiation in regenerating Amblystoma limbs. Dev Biol 1959;1:555-585

18 Hay ED, Fischman DA. Origin of the blastema in regenerating limbs of the newt Triturus viridescens. An autoradiographic study using tritiated thymidine to follow cell proliferation and migration. Dev Biol 1961;3:26-59

19 Odelberg SJ, Kollhoff A, Keating MT. Dedifferentiation of mammalian myotubes induced by msx1. Cell 2000;103(7):1099-1109

20 Harvey K, Tapon N. The Salvador-Warts-Hippo pathway-an emerging tumour-suppressor network. Nat Rev Cancer 2007;7 (3):182-191

21 Nicolay BN, Bayarmagnai B, Moon NS, Benevolenskaya EV, Frolov MV. Combined inactivation of pRB and hippo pathways induces dedifferentiation in the Drosophila retina. PLoS Genet 2010;6(4): e1000918

22 Chen ZL, Yu WM, Strickland S. Peripheral regeneration. Annu Rev Neurosci 2007;30:209-233

23 Mirsky R, Woodhoo A, Parkinson DB, Arthur-Farraj P, Bhaskaran A, Jessen KR. Novel signals controlling embryonic Schwann cell development, myelination and dedifferentiation. J Peripher Nerv Syst 2008;13(2):122-135

24 Woodhoo A, Alonso MB, Droggiti A, et al. Notch controls embryonic Schwann cell differentiation, postnatal myelination and adult plasticity. Nat Neurosci 2009;12(7):839-847

25 McGann CJ, Odelberg SJ, Keating MT. Mammalian myotube dedifferentiation induced by newt regeneration extract. Proc Natl Acad Sci U S A 2001;98(24):13699-13704

26 Suzuki K, Mitsutake N, Saenko V, et al. Dedifferentiation of human primary thyrocytes into multilineage progenitor cells without gene introduction. PLoS ONE 2011;6(4):e19354

27 Sun X, Fu X, Han W, Zhao Y, Liu H, Sheng Z. Dedifferentiation of human terminally differentiating keratinocytes into their precursor cells induced by basic fibroblast growth factor. Biol Pharm Bull 2011;34(7):1037-1045

28 Hanley SC, Assouline-Thomas B, Makhlin J, Rosenberg L. Epidermal growth factor induces adult human islet cell dedifferentiation. J Endocrinol 2011;211(3):231-239

29 Shen JF, Sugawara A, Yamashita J, Ogura H, Sato S. Dedifferentiated fat cells: an alternative source of adult multipotent cells from the adipose tissues. Int J Oral Sci 2011;3(3):117-124

30 Bicknell KA, Coxon CH, Brooks G. Can the cardiomyocyte cell cycle be reprogrammed? J Mol Cell Cardiol 2007;42(4):706-721

31 Lee J, Hong F, Kwon S, et al. Activation of p38 MAPK induces cell cycle arrest via inhibition of Raf/ERK pathway during muscle differentiation. Biochem Biophys Res Commun 2002;298 (5):765-771

32 Engel FB, Schebesta M, Duong MT, et al. p38 MAP kinase inhibition enables proliferation of adult mammalian cardiomyocytes. Genes Dev 2005;19(10):1175-1187

33 Rumyantsev PP. Interrelations of the proliferation and differentiation processes during cardiac myogenesis and regeneration. Int Rev Cytol 1977;51:186-273

34 Gassmann M, Casagranda F, Orioli D, et al. Aberrant neural and cardiac development in mice lacking the ErbB4 neuregulin receptor. Nature 1995;378(6555):390-394

35 Lee KF, Simon H, Chen H, Bates B, Hung MC, Hauser C. Requirement for neuregulin receptor erbB2 in neural and cardiac development. Nature 1995;378(6555):394-398 
36 Meyer D, Birchmeier C. Multiple essential functions of neuregulin in development. Nature 1995;378(6555):386-390

37 Okada TS. Transdifferentiation: Flexibility in Cell Differentiation. Oxford, UK: Clarendon Press; 1991

38 Tsonis PA, Madhavan M, Tancous EE, Del Rio-Tsonis K. A newt's eye view of lens regeneration. Int J Dev Biol 2004;48(8-9):975980

39 Thitoff AR, Call MK, Del Rio-Tsonis K, Tsonis PA. Unique expression patterns of the retinoblastoma $(\mathrm{Rb})$ gene in intact and lens regeneration-undergoing newt eyes. Anat Rec A Discov Mol Cell Evol Biol 2003;271(1):185-188

40 Day RC, Beck CW. Transdifferentiation from cornea to lens in Xenopus laevis depends on BMP signalling and involves upregulation of Wnt signalling. BMC Dev Biol 2011;11:54

41 Schmid V. The potential for transdifferentiation and regeneration of isolated striated muscle of medusae in vitro. Cell Differ 1988;22(3):173-182

42 Galle S, Yanze N, Seipel K. The homeobox gene Msx in development and transdifferentiation of jellyfish striated muscle. Int J Dev Biol 2005;49(8):961-967

43 Patapoutian A, Wold BJ, Wagner RA. Evidence for developmentally programmed transdifferentiation in mouse esophageal muscle. Science 1995;270(5243):1818-1821

44 Wells JM, Melton DA. Vertebrate endoderm development. Annu Rev Cell Dev Biol 1999;15:393-410

45 Deutsch G, Jung J, Zheng M, Lóra J, Zaret KS. A bipotential precursor population for pancreas and liver within the embryonic endoderm. Development 2001;128(6):871-881

46 Yang L, Li S, Hatch H, et al. In vitro trans-differentiation of adult hepatic stem cells into pancreatic endocrine hormone-producing cells. Proc Natl Acad Sci U S A 2002;99(12):8078-8083

47 Meivar-Levy I, Sapir T, Gefen-Halevi S, et al. Pancreatic and duodenal homeobox gene 1 induces hepatic dedifferentiation by suppressing the expression of CCAAT/enhancer-binding protein beta. Hepatology 2007;46(3):898-905

48 Gradwohl G, Dierich A, LeMeur M, Guillemot F. Neurogenin3 is required for the development of the four endocrine cell lineages of the pancreas. Proc Natl Acad Sci U S A 2000;97(4): 1607-1611

49 Bernardo AS, Hay CW, Docherty K. Pancreatic transcription factors and their role in the birth, life and survival of the pancreatic beta cell. Mol Cell Endocrinol 2008;294(1-2):1-9

50 Kataoka K, Han SI, Shioda S, Hirai M, Nishizawa M, Handa H. MafA is a glucose-regulated and pancreatic beta-cell-specific transcriptional activator for the insulin gene. J Biol Chem 2002;277 (51):49903-49910

51 Thorel F, Népote V, Avril I, et al. Conversion of adult pancreatic alpha-cells to beta-cells after extreme beta-cell loss. Nature 2010;464(7292):1149-1154

52 Xie H, Ye M, Feng R, Graf T. Stepwise reprogramming of B cells into macrophages. Cell 2004;117(5):663-676

53 Rodriguez-Ubreva J, Ciudad L, Gomez-Cabrero D, et al. Pre-B cell to macrophage transdifferentiation without significant promoter DNA methylation changes. Nucleic Acids Res 2012;40(5): 1954-1968

54 Kim J, Efe JA, Zhu S, et al. Direct reprogramming of mouse fibroblasts to neural progenitors. Proc Natl Acad Sci U S A 2011;108(19):7838-7843

55 Loy B, Apostolova G, Dorn R, McGuire VA, Arthur JS, Dechant G. p $38 \alpha$ and p38 $\beta$ mitogen-activated protein kinases determine cholinergic transdifferentiation of sympathetic neurons. J Neurosci 2011;31(34):12059-12067

56 Ieda M, Fu JD, Delgado-Olguin P, et al. Direct reprogramming of fibroblasts into functional cardiomyocytes by defined factors. Cell 2010;142(3):375-386

57 Numasawa Y, Kimura T, Miyoshi S, et al. Treatment of human mesenchymal stem cells with angiotensin receptor blocker improved efficiency of cardiomyogenic transdifferentiation and improved cardiac function via angiogenesis. Stem Cells 2011;29 (9):1405-1414

58 Szabo E, Rampalli S, Risueño RM, et al. Direct conversion of human fibroblasts to multilineage blood progenitors. Nature 2010;468(7323):521-526

59 Hochedlinger K, Jaenisch R. Nuclear reprogramming and pluripotency. Nature 2006;441(7097):1061-1067

60 Tanaka M, Kihara M, Meczekalski B, King GJ, Adashi EY. H1oo: a pre-embryonic $\mathrm{H} 1$ linker histone in search of a function. Mol Cell Endocrinol 2003;202(1-2):5-9

61 Govin J, Escoffier E, Rousseaux S, et al. Pericentric heterochromatin reprogramming by new histone variants during mouse spermiogenesis. J Cell Biol 2007;176(3):283-294

62 Wu F, Caron C, De Robertis C, Khochbin S, Rousseaux S. Testisspecific histone variants H2AL1/2 rapidly disappear from paternal heterochromatin after fertilization. J Reprod Dev 2008;54 (6):413-417

63 Arney KL, Bao S, Bannister AJ, Kouzarides T, Surani MA. Histone methylation defines epigenetic asymmetry in the mouse zygote. Int J Dev Biol 2002;46(3):317-320

64 Santos AP, Abranches R, Stoger E, Beven A, Viegas W, Shaw PJ. The architecture of interphase chromosomes and gene positioning are altered by changes in DNA methylation and histone acetylation. J Cell Sci 2002;115(Pt 23):4597-4605

65 Torres-Padilla ME, Bannister AJ, Hurd PJ, Kouzarides T, ZernickaGoetz M. Dynamic distribution of the replacement histone variant H3.3 in the mouse oocyte and preimplantation embryos. Int J Dev Biol 2006;50(5):455-461

66 van der Heijden GW, Dieker JW, Derijck AA, et al. Asymmetry in histone $\mathrm{H} 3$ variants and lysine methylation between paternal and maternal chromatin of the early mouse zygote. Mech Dev 2005;122(9):1008-1022

67 Mayer W, Niveleau A, Walter J, Fundele R, Haaf T. Demethylation of the zygotic paternal genome. Nature 2000;403(6769):501-502

68 Oswald J, Engemann S, Lane N, et al. Active demethylation of the paternal genome in the mouse zygote. Curr Biol 2000;10(8): 475-478

69 Hajkova P, Ancelin K, Waldmann T, et al. Chromatin dynamics during epigenetic reprogramming in the mouse germ line. Nature 2008;452(7189):877-881

70 Hajkova P. Epigenetic reprogramming-taking a lesson from the embryo. Curr Opin Cell Biol 2010;22(3):342-350

71 Okamoto I, Otte AP, Allis CD, Reinberg D, Heard E. Epigenetic dynamics of imprinted $\mathrm{X}$ inactivation during early mouse development. Science 2004;303(5658):644-649

72 Mak W, Nesterova TB, de Napoles M, et al. Reactivation of the paternal $\mathrm{X}$ chromosome in early mouse embryos. Science 2004;303(5658):666-669

73 Kurimoto K, Yamaji M, Seki Y, Saitou M. Specification of the germ cell lineage in mice: a process orchestrated by the PR-domain proteins, Blimp1 and Prdm14. Cell Cycle 2008;7(22):35143518

74 de Napoles M, Nesterova T, Brockdorff N. Early loss of Xist RNA expression and inactive $\mathrm{X}$ chromosome associated chromatin modification in developing primordial germ cells. PLOS ONE 2007;2(9):e860

75 Chuva de Sousa Lopes SM, Hayashi K, Shovlin TC, Mifsud W, Surani MA, McLaren A. X chromosome activity in mouse XX primordial germ cells. PLoS Genet 2008;4(2):e30

76 Ancelin K, Lange UC, Hajkova P, et al. Blimp1 associates with Prmt5 and directs histone arginine methylation in mouse germ cells. Nat Cell Biol 2006;8(6):623-630

77 Hajkova P, Jeffries SJ, Lee C, et al. Genome-wide reprogramming in the mouse germ line entails the base excision repair pathway. Science 2010;329(5987):78-82

78 Briggs R, King TJ. Transplantation of living nuclei from blastula cells into enucleated frogs' eggs. Proc Natl Acad Sci U S A 1952;38 (5):455-463 
79 Briggs R, King TJ. Nuclear transplantation studies on the early gastrula (Rana pipiens). I. Nuclei of presumptive endoderm. Dev Biol 1960;2:252-270

80 Gurdon JB. The developmental capacity of nuclei taken from intestinal epithelium cells of feeding tadpoles. J Embryol Exp Morphol 1962;10:622-640

81 Gurdon JB, Uehlinger V. "Fertile" intestine nuclei. Nature 1966;210(5042):1240-1241

82 Wilmut I, Beaujean N, de Sousa PA, et al. Somatic cell nuclear transfer. Nature 2002;419(6907):583-586

83 Eggan K, Baldwin K, Tackett M, et al. Mice cloned from olfactory sensory neurons. Nature 2004;428(6978):44-49

84 Cibelli JB, Stice SL, Golueke PJ, et al. Cloned transgenic calves produced from nonquiescent fetal fibroblasts. Science 1998;280 (5367):1256-1258

85 Baguisi A, Behboodi E, Melican DT, et al. Production of goats by somatic cell nuclear transfer. Nat Biotechnol 1999;17(5):456-461

86 Keefer CL, Baldassarre H, Keyston R, et al. Generation of dwarf goat (Capra hircus) clones following nuclear transfer with transfected and nontransfected fetal fibroblasts and in vitro-matured oocytes. Biol Reprod 2001;64(3):849-856

87 Wakayama T, Perry AC, Zuccotti M, Johnson KR, Yanagimachi R. Full-term development of mice from enucleated oocytes injected with cumulus cell nuclei. Nature 1998;394(6691):369-374

88 Betthauser J, Forsberg E, Augenstein M, et al. Production of cloned pigs from in vitro systems. Nat Biotechnol 2000;18(10):10551059

89 Polejaeva IA, Chen SH, Vaught TD, et al. Cloned pigs produced by nuclear transfer from adult somatic cells. Nature 2000;407 (6800):86-90

90 De Sousa PA, Dobrinsky JR, Zhu J, et al. Somatic cell nuclear transfer in the pig: control of pronuclear formation and integration with improved methods for activation and maintenance of pregnancy. Biol Reprod 2002;66(3):642-650

91 Hochedlinger $\mathrm{K}$, Jaenisch $\mathrm{R}$. Monoclonal mice generated by nuclear transfer from mature $\mathrm{B}$ and $\mathrm{T}$ donor cells. Nature 2002;415(6875):1035-1038

92 Meirelles FV, Bordignon V, Watanabe Y, et al. Complete replacement of the mitochondrial genotype in a Bos indicus calf reconstructed by nuclear transfer to a Bos taurus oocyte. Genetics 2001;158(1):351-356

93 Hwang W, Kim K, Jin Y, et al. Interspecies somatic cell nuclear transfer for the production of endangered Korean tiger. Theriogenology 2001;55:271

94 Hammer CJ, Tyler HD, Loskutoff NM, et al. Compromised development of calves (Bos gaurus) derived from in vitro-generated embryos and transferred interspecifically into domestic cattle (Bos taurus). Theriogenology 2001;55(7):1447-1455

95 Markoulaki S, Meissner A, Jaenisch R. Somatic cell nuclear transfer and derivation of embryonic stem cells in the mouse. Methods 2008;45(2):101-114

96 Huang Y, Tang X, Xie W, et al. Histone deacetylase inhibitor significantly improved the cloning efficiency of porcine somatic cell nuclear transfer embryos. Cell Reprogram 2011;13(6):513520

97 Tian J, Song J, Li H, et al. Effect of donor cell type on nuclear remodelling in rabbit somatic cell nuclear transfer embryos. Reprod Domest Anim 2012;47(4):544-552

98 Byrne JA, Pedersen DA, Clepper LL, et al. Producing primate embryonic stem cells by somatic cell nuclear transfer. Nature 2007;450(7169):497-502

99 Kato Y, Tsunoda Y. Role of the donor nuclei in cloning efficiency: can the ooplasm reprogram any nucleus? Int J Dev Biol 2010;54 (11-12):1623-1629

100 Wilmut I, Schnieke AE, McWhir J, Kind AJ, Campbell KH. Viable offspring derived from fetal and adult mammalian cells. Nature 1997;385(6619):810-813
101 Campbell KH, McWhir J, Ritchie WA, Wilmut I. Sheep cloned by nuclear transfer from a cultured cell line. Nature 1996;380 (6569):64-66

102 Kato Y, Tani T, Tsunoda Y. Cloning of calves from various somatic cell types of male and female adult, newborn and fetal cows. J Reprod Fertil 2000;120(2):231-237

103 Kato Y, Imabayashi H, Mori T, et al. Nuclear transfer of adult bone marrow mesenchymal stem cells: developmental totipotency of tissue-specific stem cells from an adult mammal. Biol Reprod 2004;70(2):415-418

104 Sung LY, Gao S, Shen H, et al. Differentiated cells are more efficient than adult stem cells for cloning by somatic cell nuclear transfer. Nat Genet 2006;38(11):1323-1328

105 Yamanaka S, Blau HM. Nuclear reprogramming to a pluripotent state by three approaches. Nature 2010;465(7299):704-712

106 Blau HM, Chiu CP, Webster C. Cytoplasmic activation of human nuclear genes in stable heterocaryons. Cell 1983;32(4):11711180

107 Harris H, Watkins JF, Ford CE, Schoefl GI. Artificial heterokaryons of animal cells from different species. J Cell Sci 1966;1(1):1-30

108 Wright WE. Induction of muscle genes in neural cells. J Cell Biol 1984;98(2):427-435

109 Baron MH, Maniatis T. Rapid reprogramming of globin gene expression in transient heterokaryons. Cell 1986;46(4):591-602

110 Spear BT, Tilghman SM. Role of alpha-fetoprotein regulatory elements in transcriptional activation in transient heterokaryons. Mol Cell Biol 1990;10(10):5047-5054

111 Chiu CP, Blau HM. Reprogramming cell differentiation in the absence of DNA synthesis. Cell 1984;37(3):879-887

112 Miller SC, Pavlath GK, Blakely BT, Blau HM. Muscle cell components dictate hepatocyte gene expression and the distribution of the Golgi apparatus in heterokaryons. Genes Dev 1988;2(3):330340

113 Tada M, Tada T, Lefebvre L, Barton SC, Surani MA. Embryonic germ cells induce epigenetic reprogramming of somatic nucleus in hybrid cells. EMBO J 1997;16(21):6510-6520

114 Tada M, Takahama Y, Abe K, Nakatsuji N, Tada T. Nuclear reprogramming of somatic cells by in vitro hybridization with ES cells. Curr Biol 2001;11(19):1553-1558

115 Cowan CA, Atienza J, Melton DA, Eggan K. Nuclear reprogramming of somatic cells after fusion with human embryonic stem cells. Science 2005;309(5739):1369-1373

116 Pereira CF, Terranova R, Ryan NK, et al. Heterokaryon-based reprogramming of human B lymphocytes for pluripotency requires Oct4 but not Sox2. PLoS Genet 2008;4(9):e1000170

117 Bhutani N, Brady JJ, Damian M, Sacco A, Corbel SY, Blau HM. Reprogramming towards pluripotency requires AID-dependent DNA demethylation. Nature 2010;463(7284):1042-1047

118 Agarwal S, Daley GQ. AID for reprogramming. Cell Res 2010;20 (3):253-255

119 Durcova-Hills G, Tang F, Doody G, Tooze R, Surani MA. Reprogramming primordial germ cells into pluripotent stem cells. PLoS ONE 2008;3(10):e3531

120 Durcova-Hills G, Adams IR, Barton SC, Surani MA, McLaren A. The role of exogenous fibroblast growth factor- 2 on the reprogramming of primordial germ cells into pluripotent stem cells. Stem Cells 2006;24(6):1441-1449

121 Youngren KK, Coveney D, Peng X, et al. The Ter mutation in the dead end gene causes germ cell loss and testicular germ cell tumours. Nature 2005;435(7040):360-364

122 Muller AJ, Teresky AK, Levine AJ. A male germ cell tumorsusceptibility-determining locus, pgct1, identified on murine chromosome 13. Proc Natl Acad Sci U S A 2000;97(15):84218426

123 Kimura T, Tomooka M, Yamano N, et al. AKT signaling promotes derivation of embryonic germ cells from primordial germ cells. Development 2008;135(5):869-879 
124 Shamblott MJ, Axelman J, Littlefield JW, et al. Human embryonic germ cell derivatives express a broad range of developmentally distinct markers and proliferate extensively in vitro. Proc Natl Acad Sci U S A 2001;98(1):113-118

125 Shamblott MJ, Axelman J, Wang S, et al. Derivation of pluripotent stem cells from cultured human primordial germ cells. Proc Natl Acad Sci U S A 1998;95(23):13726-13731

126 Schneuwly S, Klemenz R, Gehring WJ. Redesigning the body plan of Drosophila by ectopic expression of the homoeotic gene Antennapedia. Nature 1987;325(6107):816-818

127 Davis RL, Weintraub H, Lassar AB. Expression of a single transfected cDNA converts fibroblasts to myoblasts. Cell 1987;51 (6):987-1000

128 Takahashi K, Yamanaka S. Induction of pluripotent stem cells from mouse embryonic and adult fibroblast cultures by defined factors. Cell 2006;126(4):663-676

129 Welstead GG, Brambrink T, Jaenisch R. Generating iPS cells from MEFS through forced expression of Sox-2, Oct-4, c-Myc, and Klf4. J Vis Exp 2008;(14):

130 Yamanaka S. Pluripotency and nuclear reprogramming. Philos Trans R Soc Lond B Biol Sci 2008;363(1500):2079-2087
131 Hamilton B, Feng Q Ye M, Welstead GG. Generation of induced pluripotent stem cells by reprogramming mouse embryonic fibroblasts with a four transcription factor, doxycycline inducible lentiviral transduction system. J Vis Exp 2009;(33):

132 Nakagawa M, Koyanagi M, Tanabe K, et al. Generation of induced pluripotent stem cells without Myc from mouse and human fibroblasts. Nat Biotechnol 2008;26(1):101-106

133 Aasen T, Raya A, Barrero MJ, et al. Efficient and rapid generation of induced pluripotent stem cells from human keratinocytes. Nat Biotechnol 2008;26(11):1276-1284

134 Giorgetti A, Montserrat N, Rodriguez-Piza I, Azqueta C, Veiga A, Izpisúa Belmonte JC. Generation of induced pluripotent stem cells from human cord blood cells with only two factors: Oct4 and Sox2. Nat Protoc 2010;5(4):811-820

135 González F, Boué S, Izpisúa Belmonte JC. Methods for making induced pluripotent stem cells: reprogramming à la carte. Nat Rev Genet 2011;12(4):231-242

136 Tiscornia G, Vivas EL, Izpisúa Belmonte JC. Diseases in a dish: modeling human genetic disorders using induced pluripotent cells. Nat Med 2011;17(12):1570-1576 